\title{
Turion production and nutrient reserves in Potamogeton crispus are influenced by sediment nutrient level
}

\author{
Dong Xie, Dan Yu* \\ The National Field Station of Freshwater Ecosystem of Liangzi Lake, College of Life Science, Wuhan University, Wuhan, \\ 430072, PR China
}

\begin{abstract}
The influence of sediment nutrient content on asexual propagule production in plants is poorly understood, especially in submersed macrophytes. To improve the understanding of turion (an aboveground asexual propagule) production, Potamogeton crispus L. was planted in 2 experimental conditions that differed in their levels of sediment nutrients. After 10 wk of growth, sediment nutrient level had significantly impacted the plants' vegetative and reproductive traits. Most vegetative trait measures of $P$. crispus (e.g. leaf mass fraction and stem mass fraction) were higher when plants were grown in nutrient-rich sediment compared with plants grown in nutrient-poor sediment. Reproductive trait measures (e.g. turion mass fraction and individual turion biomass) were higher in plants grown in nutrient-poor sediment compared with plants grown in nutrient-rich sediment. Plants grown in nutrient-rich sediment produced a larger number of small turions (<50 mg), in which more nutrients (total nitrogen and total phosphorus) were stored; plants grown in nutrient-poor sediment produced more large turions (>100 mg) and stored more total nonstructural carbohydrate (the major proportion of which was starch) in them. Path analysis revealed that total plant biomass (strong positive effect), leaf and stem biomass (weak negative effects) had direct effects on total turion biomass, which consequently affected turion size and number. Moreover, ramet number and mean shoot height also had weak but direct effects (both negative effects) on turion size and number. These results demonstrate that sediment nutrient content mediates plant vegetative traits and can subsequently affect turion production and reserves in $P$. crispus.
\end{abstract}

KEY WORDS: Asexual reproduction · Potamogeton crispus - Reserves - Sediment nutrients · Turion

Resale or republication not permitted without written consent of the publisher

\section{INTRODUCTION}

Many environmental factors affect reproductive output in plants (e.g. Hartnett 1990, Schmid et al. 1994, Worley \& Harder 1996, Stoll et al. 1998, Jongejans et al. 2006). Nutrients in sediment are among the factors that have been most widely studied. Indeed, even small variations in nutrient availability can create large differences in plant growth and reproductive output (Sugiyama \& Bazzaz 1998, Bonser \& Aarssen 2003). Plant size, biomass allocation, plant structure, and total rhizome length all vary substantially according to sediment nutrients (Stoll et al. 1998, Müller et al. 2000, Vojtíšková et al. 2004, Maire et al. 2009). These traits may determine both the ongoing fitness of plants and the performance of future propagules.

Under varying nutrient conditions, plants presumably allocate an optimal level of resources to propagules. For instance, larger tubers are more likely to survive in nutrient-poor substrates, whereas abundant smaller tubers are common in nutrient-rich sub- 
strates (Hangelbroek et al. 2003). However, much of the research dedicated to understanding the relationship between sediment nutrients and reproductive output has focused on sexual reproduction. Although the influence of sediment nutrients on clonal plants has begun to receive attention, we do not have a thorough understanding of asexual propagation, particularly for plants in aquatic habitats (Slade \& Hutchings 1987, Dong et al. 1997, Hangelbroek et al. 2003, Xiao et al. 2006). Asexual reproduction is generally assumed to be more common in aquatic habitats than in terrestrial habitats because of unfavorable ecological conditions for sexual reproduction, e.g. decreased pollination success and low reproductive success (for a review, see Santamaría 2002). Indeed, many asexual propagules of aquatic macrophytes can self-initiate abscission-examples include auto-fragments of Myriophyllum spicatum L. (Smith et al. 2002) and turions of M. verticillatum $L$. (Weber \& Noodén 2005). Therefore, aquatic plants are very suitable for examining the relationship between sediment nutrients and successful asexual reproduction.

For a given amount of resources that a plant can allocate to propagation, there is a compromise between propagule size and number (i.e. the size-number trade-off, Smith \& Fretwell 1974). Previous studies have suggested that this trade-off also exists in submersed macrophytes. For example, Potamogeton pectinatus L. balances size and number in its production of tubers (below-ground asexual propagules) (Santamaría \& Rodríguez-Gironés 2002). Interestingly, the size-number trade-off in $P$. pectinatus tubers differs significantly among field sites (Santamaría \& Rodríguez-Gironés 2002), which suggests that sitespecific conditions (e.g. sediment type, nutrient conditions and light levels) may contribute to the way in which resources are partitioned into propagule size and number.

Potamogeton crispus L. is a perennial aquatic macrophyte native to Europe and Asia that is dominant in lakes, rivers and ponds throughout China (Xie et al. 2003). Unlike other aquatic macrophytes, $P$. crispus simultaneously flowers and produces aboveground turions almost continuously from late May to late October (Sastroutomo 1981, Wu et al. 2009). Turions are resistant plant buds found on certain aquatic plants that allow the plants to survive winter in a vegetative state without setting seeds (Rogers \& Breen 1980, Kunii 1982). Large nutrient reserves may be stored in turions, which allow the turions to serve multiple functions for the plant including storage, propagation and dispersal (Jian et al. 2003, Woolf \&
Madsen 2003, Adamec 2010). Although P. crispus produces seeds, the viability and germination of these seeds is reportedly very low $(0.001 \%$; Rogers \& Breen 1980), which supports the hypothesis that the primary means of propagation for this species is the dispersal of turions (Jian et al. 2003, Woolf \& Madsen 2003). Field studies have indicated that turion production is high in $P$. crispus. For example, densities of 1000 to 1500 turions $\mathrm{m}^{-2}$ have been documented in South Africa (Rogers \& Breen 1980). In addition, densities ranging from 200 to 1700 turions $\mathrm{m}^{-2}$ have been reported in Japan (Kunii 1982), and densities ranging from 726 to 2713 turions $\mathrm{m}^{-2}$ have been documented in ponds in the USA (Woolf \& Madsen 2003). Successful propagation from turions (up to $60 \%$ of turions germinate, Rogers \& Breen 1980) results in the formation of monospecific stands of $P$. crispus, a degradation of water quality (the aboveground portions of $P$. crispus decompose in summer) and a reduction in the relative abundance and richness of other local species (Bolduan et al. 1994).

In this study, we examined how vegetative growth and turion production in Potamogeton crispus were affected when the plants were grown in 2 types of sediment that had different nutrient content. The following questions were addressed: (1) Does P. crispus adjust its vegetative traits (e.g. overall plant biomass) and biomass partitioning in response to different levels of sediment nutrients? (2) Does P. crispus adjust its turion production (e.g. turion number and size) and storage matter in response to different levels of sediment nutrients?

\section{MATERIALS AND METHODS}

\section{Sample site and collection}

This study was conducted at The National Field Station of Freshwater Ecosystem of Liangzi Lake, China ( $\left.30^{\circ} 5^{\prime}-30^{\circ} 18^{\prime} \mathrm{N}, 114^{\circ} 21^{\prime}-114^{\circ} 39^{\prime} \mathrm{E}\right)$. In March 2008, 100 apical shoots of Potamogeton crispus (approximately $10 \mathrm{~cm}$ long with 6 to 7 leaves) were collected from randomly selected plants in Liangzi Lake. The collection sites were covered by monospecific stands of $P$. crispus during March. The water depth at the collection site was 0.6 to $1.2 \mathrm{~m}$ and the site contained both muddy substratum, with a total nitrogen (TN) content of $2.86 \mathrm{mg} \mathrm{g}^{-1}$ and a total phosphorus (TP) content of $0.13 \mathrm{mg} \mathrm{g}^{-1}$, and sandy substratum, with a TN content of $0.04 \mathrm{mg} \mathrm{g}^{-1}$ and a TP content of $0.001 \mathrm{mg} \mathrm{g}^{-1}$. The apical shoots were 
transplanted into containers filled with sand and water to a depth of $20 \mathrm{~cm}$. Containers were stored in a greenhouse (water temperature $25.62 \pm 2.17^{\circ} \mathrm{C}$; light intensity $1923 \pm 37.45 \mu \mathrm{mol}$ photons $\mathrm{m}^{-2} \mathrm{~s}^{-1}$, mean $\pm \mathrm{SE}$ ) for approximately $2 \mathrm{wk}$ until the plants had well-developed root systems.

\section{Experimental design}

The experiment was conducted from April 9, 2008 to June 18, 2008. During the experimental period, individual plants were grown in either of 2 test sediments and each treatment was replicated 24 times for a total of 48 individual plants. Two different sediment nutrient levels were tested: a nutrient-poor sediment, which consisted of $25 \%$ muddy substratum mixed with $75 \%$ sand substratum and had a TN and a TP content of $0.74 \mathrm{mg} \mathrm{g}^{-1}$ and $0.03 \mathrm{mg} \mathrm{g}^{-1}$, respectively; the nutrient-rich sediment consisted of $75 \%$ muddy substratum mixed with $25 \%$ sand substratum and had a TN and a TP content of $2.20 \mathrm{mg} \mathrm{g}^{-1}$ and $0.09 \mathrm{mg} \mathrm{g}^{-1}$, respectively. Both substrata were obtained from the collection site in Liangzi Lake. Each plant was individually placed as an apical shoot into a plastic pot (diameter $25 \mathrm{~cm}$, height $20 \mathrm{~cm}$ ) along with $4 \mathrm{~kg}$ (dry weight) of substratum. Each pot was placed in a fiberglass tank (diameter $100 \mathrm{~cm}$, height $100 \mathrm{~cm}$ ) and the tanks were filled with ambient lake water to a depth of $100 \mathrm{~cm}$ (TN $0.71 \mathrm{mg} \mathrm{l}^{-1}$, TP $0.04 \mathrm{mg} \mathrm{l}^{-1}$ ). All tanks (48 tanks in total) were placed outdoors in a block design with 6 replicated blocks (four tanks from each treatment were randomly placed in one block). At the beginning of the experiment, the plants had a fresh weight of $0.48 \pm 0.02 \mathrm{~g}$ (mean $\pm \mathrm{SE}$ ) and a total height of $24.8 \pm 0.5 \mathrm{~cm}$ (mean $\pm \mathrm{SE}$ ). Water temperatures and light intensities in the experimental tanks were recorded at noon every $3 \mathrm{~d}$ (the water temperature was $26.40 \pm 3.61^{\circ} \mathrm{C}$ and the light intensity was $2132 \pm 38.23 \mu \mathrm{mol}$ photons $\mathrm{m}^{-2} \mathrm{~s}^{-1}$; mean $\pm \mathrm{SE}, \mathrm{n}=24$ ). To reduce the influence of algae on plant growth, the water in the tanks was changed weekly.

\section{Plant harvest}

After 10 wk of growth, plants from each nutrient treatment were carefully uprooted and rinsed to remove sediment from the roots. Fresh weights and stem lengths were recorded for harvested plants before separating each plant into roots, stems, leaves, turions and rhizomes. Plant tissue samples were dried at $80^{\circ} \mathrm{C}$ for $72 \mathrm{~h}$ before weighing. All vegetative trait measures (root, stem, rhizome and turion mass fractions) were calculated as dry weight (DW) percentages of the total plant biomass, and individual turion biomass was calculated as the average DW of individual turions.

\section{Chemical analysis}

Upon collection, water, sediment and turion samples were digested with $\mathrm{H}_{2} \mathrm{SO}_{4}$ and analyzed for TN and TP content. The TN and TP content were reported on a \%DW basis. Total nonstructural carbohydrate (TNC) content was measured using the perchloric acid/anthrone method (Morris 1948) by combining the soluble sugar and starch fractions. The soluble sugar and starch contents were reported as $\mathrm{mg} \mathrm{g}^{-1} \mathrm{DW}$. For further details on sample preparation and analytical methods, see Xie \& Yu (2011). TN, TP and TNC measurements were collected in triplicate.

\section{Statistical analysis}

All data were $\log (x)$ transformed to ensure homoscedasticity and normality of residuals. The differences among blocks were treated as random effects, and there were no significant effects ( $p>$ 0.05). Thus, the statistical differences between nutrient levels were analyzed using $t$-tests $(\alpha=$ 0.05). In addition, we performed a path analysis of partial correlation coefficients obtained from a hierarchical set of multiple regressions, which allowed us to evaluate the effects of vegetative traits (e.g. total plant biomass, leaf and stem biomass) on total turion production and its allocation into turion size and number (Santamaría \& Rodríguez-Gironés 2002, Hangelbroek \& Santamaría 2004). All data were analyzed using SPSS 13.0 software (SPSS, Chicago).

\section{RESULTS}

After 10 wk of growth, we observed significant differences in total plant biomass between the rich and poor nutrient conditions (Table 1). Specifically, Potamogeton crispus grown in nutrient-rich sediment had higher stem and leaf mass fractions, and lower root mass fractions compared with plants grown in nutrient-poor sediment. Rhizome mass fraction, however, 
Table 1. Potamogeton crispus. Traits of the macrophyte grown in nutrient-poor and nutrient-rich sediments from Liangzi Lake, China. Absolute values (mean $\pm \mathrm{SE}$ ) are shown with $t$-values and $\mathrm{p}$-values from $t$-test. All data were transformed using a $\log (\mathrm{x})$ function. Significant $\mathrm{p}$-values $(\mathrm{p}<0.05)$ are indicated in bold

\begin{tabular}{|c|c|c|c|c|c|}
\hline Trait & $\begin{array}{c}\text { Nutrient-poor } \\
\text { sediment }\end{array}$ & $\begin{array}{c}\text { Nutrient-rich } \\
\text { Sediment }\end{array}$ & $\mathrm{n}$ & $t$ & $\mathrm{p}$ \\
\hline \multicolumn{6}{|l|}{ Vegetative traits } \\
\hline Total plant biomass (g) & $4.50 \pm 0.4$ & $6.67 \pm 0.6$ & 48 & 2.817 & 0.007 \\
\hline Root mass fraction (\%) & $5.49 \pm 0.6$ & $3.89 \pm 0.3$ & 48 & -2.261 & 0.029 \\
\hline Stem mass fraction $(\%)$ & $15.05 \pm 0.7$ & $25.50 \pm 1.3$ & 48 & 7.629 & $<0.001$ \\
\hline Leaf mass fraction $(\%)$ & $20.34 \pm 1.2$ & $38.52 \pm 2.1$ & 48 & 7.160 & $<0.001$ \\
\hline Rhizome stem mass fraction (\%) & $1.90 \pm 0.1$ & $1.53 \pm 0.1$ & 48 & -1.866 & 0.068 \\
\hline Root:shoot ratio (\%) & $5.91 \pm 0.7$ & $4.07 \pm 0.3$ & 48 & -2.275 & 0.028 \\
\hline Ramet number & $10.96 \pm 0.6$ & $14.67 \pm 0.9$ & 48 & 3.255 & 0.002 \\
\hline Rhizome stem length (cm) & $78.33 \pm 5.2$ & $87.03 \pm 6.7$ & 48 & 0.644 & 0.523 \\
\hline Rhizome internode length (cm) & $7.38 \pm 0.3$ & $6.30 \pm 0.3$ & 48 & -2.754 & 0.008 \\
\hline Mean shoot height $(\mathrm{cm})$ & $60.37 \pm 2.3$ & $80.19 \pm 3.1$ & 48 & 4.647 & $<0.001$ \\
\hline \multicolumn{6}{|l|}{ Turion traits } \\
\hline Turion mass fraction (\%) & $57.22 \pm 2.2$ & $30.55 \pm 2.9$ & 48 & -6.363 & $<0.001$ \\
\hline Individual turion biomass (mg) & $85.2 \pm 6.0$ & $56.4 \pm 5.1$ & 48 & -3.777 & $<0.001$ \\
\hline Turion number & $31.21 \pm 2.8$ & $36.79 \pm 3.8$ & 48 & 0.710 & 0.487 \\
\hline (Stem+leaf):turion ratio (\%) & $69.00 \pm 8.1$ & $290.44 \pm 39.8$ & 48 & 11.332 & $<0.001$ \\
\hline
\end{tabular}

effects of leaf and stem biomass. However, these 3 vegetative traits did not directly affect turion number or size (Fig. 2). Total turion biomass had a strong positive effect on both turion number and size, which were negatively correlated (Fig. 2). Ramet number had a direct negative effect on turion number, and mean shoot height had a direct negative effect on both turion number and size; however, the negative effects of shoot height were weaker than the effect of turion production on turion number and size (Fig. 2). Root biomass, rhizome stem biomass, rhizome stem length and

was similar regardless of nutrient condition. Thus, plants grown in nutrient-poor sediment had significantly higher root:shoot ratios than plants grown in nutrient-rich sediment. Plants grown in nutrient-rich sediment had shorter rhizome internode lengths, which led to an increased number of ramets. There was no difference in total rhizome length between the 2 sediment treatments. Plants grown in nutrientrich sediment were taller than those grown in nutrient-poor sediment (Table 1).

Although the total number of turions was similar between the 2 nutrient conditions, plants grown in nutrient-poor sediment had significantly greater turion mass fractions and (stem+leaf):turion ratios (Table 1). The biomass of individual turions was greater in nutrient-poor sediment compared with nutrient-rich sediment (Table 1). Furthermore, the size of turions was significantly different between the 2 nutrient treatments. Plants grown in nutrientrich sediment tended to produce more small turions (<50 mg), whereas plants grown in nutrient-poor sediment tended to produce more large turions (>100 mg) (Fig. 1).

The path analysis revealed that total plant biomass, leaf and stem biomass had direct effects on turion production and that these effects together explained $94.6 \%$ of the variation in turion production. Among these traits, the positive effect of total plant biomass on turion production was stronger than the negative rhizome internode length did not have significant effects on any trait.

Starch content was higher in turions produced in nutrient-poor sediment compared with turions produced in nutrient-rich sediment, but soluble sugar content was similar (Fig. 3). Furthermore, the majority of TNC in turions was starch ( 70 to $99 \%$ and 75 to $99 \%$ in turions produced in nutrient-poor and nutrient-rich sediment, respectively). Plants grown in nutrient-rich sediment produced turions with higher TN and TP content than equivalent plants grown in nutrient-poor sediment (Fig. 3).

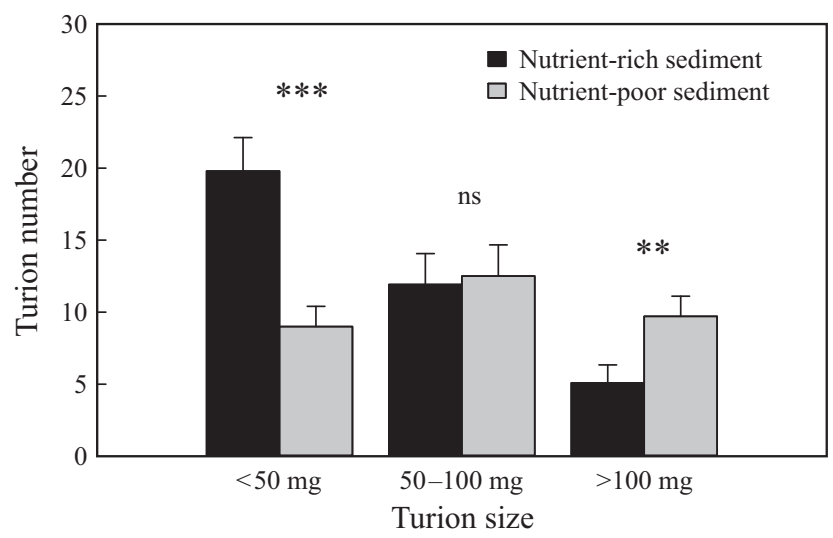

Fig. 1. Potamogeton crispus. Turion number (mean $\pm \mathrm{SE}, \mathrm{n}=$ $24)$ in relation to turion size categories (dry mass) under nutrient-poor and nutrient-rich sediment regimes. The results were analyzed with a $t$-test. ${ }^{* * *} \mathrm{p}<0.001,{ }^{* *} \mathrm{p}<0.01$, ns $\mathrm{p}>0.05$ 


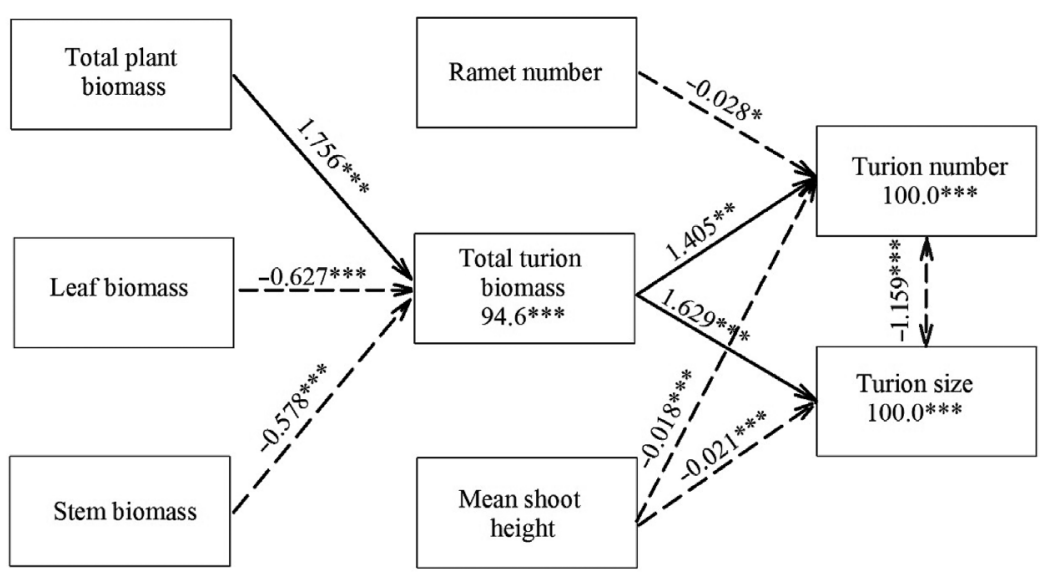

Fig. 2. Results of the path analysis for the effects of traits on turion size and number in Potamogeton crispus. All possible pathways were tested, but only the significant relationships are shown here. Solid arrows indicate positive correlations, and dashed arrows show negative correlations. Partial correlation coefficients and their significance levels are indicated on the arrows, and the percentages of explained variation (adjusted $R^{2}$ ), and the significance level of the multiple regression analysis are indicated within boxes: ${ }^{* * *} p<0.001$, ${ }^{* *} \mathrm{p}<0.01,{ }^{*} \mathrm{p}<0.05$

\section{DISCUSSION}

The present study shows that the elevated nutrient levels in the sediment of Liangzi Lake support greater total biomass in Potamogeton crispus plants. These findings are consistent with our previous studies on other plant species (Xie et al. 2010, Xie \&

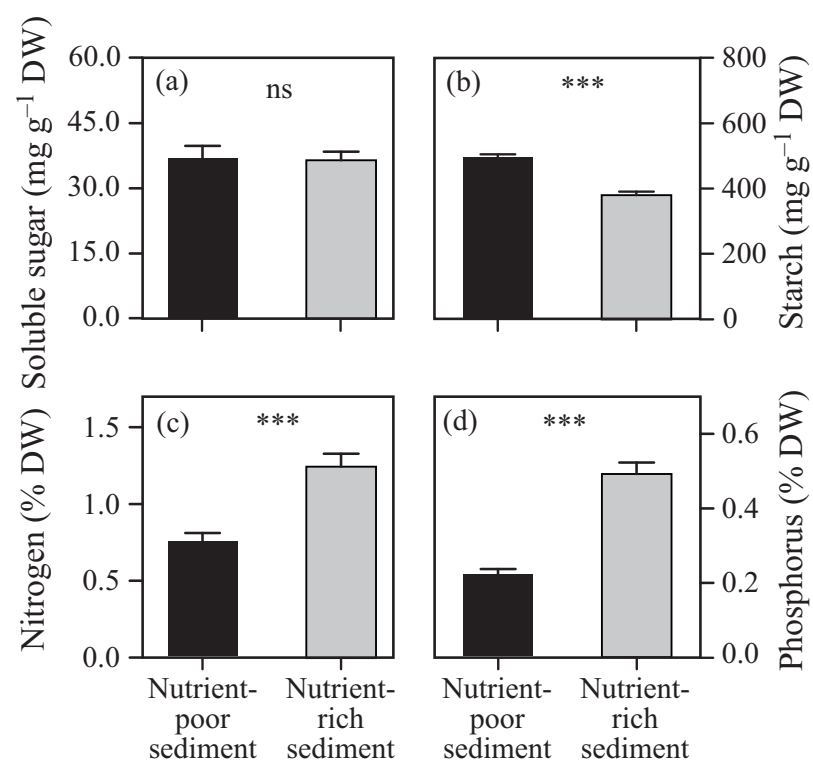

Fig. 3. Potamogeton crispus. Differences in (a) soluble sugar, (b) starch, (c) nitrogen and (d) phosphorus content of turions between the sediment nutrient treatments. Data are means $\pm \mathrm{SE}(\mathrm{n}=72)$. The results were analyzed with a $t$-test: ${ }^{* * *} \mathrm{p}<$ 0.001 , ns $\mathrm{p}>0.05$
Yu 2011). In nutrient-rich sediment, the significant increase in total plant biomass and decrease in root:shoot ratio were caused by significant increases in leaf and stem biomass. These findings are similar to those of several previous studies in both terrestrial and aquatic clonal plants (Müller et al. 2000, Vojtíšková et al. 2004). Although we found that rhizome stem length was similar between treatments, rhizome internode length was shorter and ramet number was significantly greater in plants grown in nutrient-rich sediment compared with plants grown in nutrientpoor sediment; these findings are also consistent with previous studies of clonal plants (Slade \& Hutchings 1987, Stoll et al. 1998, Xiao et al. 2006, Wang $\& \mathrm{Yu}$ 2007). These vegetative responses (i.e. changes in leaf mass fraction, stem mass fraction, root:shoot ratio and rhizome internode growth) resulted from exposure to different nutrient conditions and indicate the plasticity of $P$. crispus.

Our results confirm that total plant biomass has a strong direct positive effect on turion production, which is consistent with previous field observations in Potamogeton crispus (Kunii 1982). Kunii (1982) also observed that tall-growing plants tended to produce small ramets through rhizomes. Both ramet number and mean shoot height had weak negative effects on turion number and mean shoot height also had a weak negative effect on turion size in our experiment. This may be due to the innate reproductive strategy of perennial clonal plants. Indeed, perennial clonal plants grown in nutrient-rich sediment increase their clonal growth to enhance their competitive abilities and nutrient influxes and they decrease their production of asexual propagules (Takada \& Nakajima 1996, Jongejans et al. 2006).

Turions produced by Potamogeton crispus can act as storage organs to buffer against unfavorable ecological conditions (Adamec 2010). Although the total number of turions for plants grown in nutrient-rich versus nutrient-poor sediments was similar, individual turion biomass was higher in plants grown in nutrient-poor sediment. These results may be explained by the finding that nutrient limitation causes resources to be re-allocated to carbohydrate reserves instead of being utilized for vegetative growth processes (Hangelbroek et al. 2003). For instance, plants in stressful habitats allocate more 
dry mass to the development of storage organs than plants in favorable habitats (Puijalon et al. 2008). The plasticity of $P$. crispus was demonstrated by its ability to re-allocate resources to carbohydrate reserves (turions in this case) when faced with nutrient-poor conditions.

Turion size and number were negatively related in our study, and this trade-off differed significantly between plants grown in nutrient-rich sediment and those grown in nutrient-poor sediment. Plants grown in nutrient-poor sediment produced larger propagules, whereas plants grown in nutrient-rich sediment produced smaller propagules. These findings are consistent with a previous study of Potamogeton pectinatus (Hangelbroek et al. 2003). This pattern can be explained in several ways. Firstly, plants may decrease their investment in leaf and stem biomass, which can result in a decreased supply of carbohydrate to newly growing propagules and allow plants to store carbohydrate in previously formed turions under conditions of nutrient-poor sediment (Hangelbroek et al. 2003). Secondly, differences in the timing of turion formation may explain why plants grown in nutrient-rich sediment produced smaller turions. Because we harvested all plants after 10 wk of growth, we did not fully account for differences in the length of the turion formation period. For plants grown in nutrient-poor sediment, turion formation probably began earlier, whereas plants grown in nutrient-rich sediment allocated more carbohydrate to vegetative growth.

Carbohydrate reserves play an important role in propagule performance (e.g. survival, sprouting and spread) (Spencer \& Ksander 1996, Suzuki \& Stuefer 1999, Werger \& Huber 2006), and in determining whether the propagules of aquatic plants sink or float. Studies have shown that turions of Potamogeton crispus contain high TNC, particularly starch (Woolf \& Madsen 2003). This starch is relatively dense $\left(1.44 \mathrm{~g} \mathrm{~cm}^{-3}\right)$ and may alter the density of aquatic plant propagules; however, other factors, such as lacunal volume, are also important (Weber \& Noodén 2005). In fact, an increase in starch content can increase propagule density enough to cause sinking-for example, stems of Elodea nuttallii (Planch) St. John (Kunii 1984) and turions of Myriophyllum verticillatum (Weber \& Noodén 2005). In our experiment, the starch content in turions from nutrient-poor sediment was higher compared with turions from nutrient-rich sediment. Large amounts of starch stored in turions from plants grown in nutrient-poor sediment would probably enable turions to rapidly sink. Interestingly, TN and TP content were higher in turions from nutrient-rich sediment. This result is consistent with previous studies, which show that plants grown in infertile environments accumulate more carbohydrates but store fewer nutrients in propagules (Bloom et al. 1985). In addition, other studies have suggested that propagule production is limited by nutrient shortages (Hangelbroek et al. 2003, Xie et al. 2010, Xie \& Yu 2011). Moreover, the predominant function of nutrient reserves in turions may be to promote plant survival during dormancy (e.g. to support the growth of new roots or shoots for mineral uptake from water or sediment, Adamec 2010). Therefore, it is possible that higher nutrient levels in turions from nutrient-rich sediment facilitate survival and establishment during the dispersal process.

Although previous studies have shown that the seedling growth and plant distribution of Potamogeton species can tolerant a wide range of sediment grain sizes (Nicholson et al. 1975, Ailstock et al. 2010), our study was limited by mixing different types of substrata to create 2 different nutrient levels. We did not perform a comprehensive examination of how other abiotic factors (e.g. drainage rate, nutrient adsorption, biological availability or oxygen circulation) may interact with sediment nutrients to determine turion production. For instance, the growth of submerged species is negatively correlated with mean dissolved organic carbon content in the interstitial waters of the sediment (Barko \& Smart 1983). Therefore, in further studies regarding the impact of sediment nutrient on asexual reproduction, the possible roles of other abiotic conditions should be considered.

\section{CONCLUSIONS}

This study revealed that, under experimental conditions, total plant biomass has a strong direct positive effect on turion production in Potamogeton crispus. The influence of sediment nutrient level on vegetative and reproductive growth was examined, and we found that the vegetative trait measures (e.g. total plant biomass, leaf and stem mass fractions) of plants grown in nutrient-rich sediment significantly increased whereas reproductive trait measures (e.g. turion mass fraction and turion size) significantly decreased. Our findings also suggest that increases in some vegetative traits (e.g. leaf and stem biomass and ramet number) of plants grown in nutrient-rich sediment have weak negative effects on turion traits. Although nutrient reserves were significantly lower 
in turions from nutrient-poor sediment, the amount of carbohydrate stored in these turions was significantly higher, which suggests that nutrient shortages may result in decreased turion production. Furthermore, there are various factors that may influence turion production, ranging from sediment nutrients to abiotic environmental aspects of the sediment. Thus, additional studies on these topics should be performed.

Acknowledgements. We thank Dr. Keyan Xiao, Wen Xiong, Qiang Wang, Lingfei Yu and Hui Wang for laboratory/field assistance and helpful discussion. We also greatly appreciate the valuable comments on an early version of the manuscript of 2 anonymous reviewers. This research was supported by the National Natural Science Foundation of China (30930011 and 30770363).

\section{LITERATURE CITED}

Adamec L (2010) Tissue mineral nutrient content in turions of aquatic plants: does it represent a storage function? Fundam Appl Limnol 176:145-151

> Ailstock MS, Shafer DJ, Magoun AD (2010) Effects of planting depth, sediment grain size, and nutrients on Ruppia maritima and Potamogeton perfoliatus seeding emergence and growth. Restor Ecol 18:574-583

Barko JW, Smart RM (1983) Effects of organic matter additions to sediment on the growth of aquatic plants. J Ecol 71:161-175

Bloom AJ, Chapin FS III, Mooney HA (1985) Resource limitation in plants - an economic analogy. Annu Rev Ecol Syst 16:363-392

Bolduan BR, van Eeckhout GC, Quade HW, Gannon JE (1994) Potamogeton crispus-the other invader. Lake Reservior Manage 10:113-125

> Bonser SP, Aarssen LW (2003) Allometry and development in herbaceous plants: functional responses of meristem allocation to light and nutrient availability. Am J Bot 90: 404-412

> Dong M, During HJ, Werger MJA (1997) Clonal plasticity in response to nutrient availability in the pseudoannual herb, Trientalis europaea L. Plant Ecol 131:233-239

Hangelbroek HH, Santamaría L (2004) Regulation of propagule size in the aquatic pseudo-annual Potamogeton pectinatus: Are genetic and maternal non-genetic effects additive? Evol Ecol Res 6:147-161

Hangelbroek HH, Santamaría L, de Boer T (2003) Local adaptation of the pondweed Potamogeton pectinatus to contrasting substrate types mediated by changes in propagule provisioning. J Ecol 91:1081-1092

Hartnett DC (1990) Size-dependent allocation to sexual and vegetative reproduction in four clonal composites. Oecologia 84:254-259

Jian Y, Li B, Wang J, Chen J (2003) Control of turion germination in Potamogeton crispus. Aquat Bot 75:59-69

> Jongejans E, de Kroon H, Berendse F (2006) The interplay between shifts in biomass allocation and costs of reproduction in four grassland perennials under simulated successional change. Oecologia 147:369-378

Kunii H (1982) Life cycle and growth of Potamogeton crispus
L. in a shallow pond, Ojaga-ike. J Plant Res 95:109-124 Kunii H (1984) Effects of light intensity on the growth and buoyancy of detached Elodea nuttallii (Planch.) St. John during winter. J Plant Res 97:287-295

> Maire V, Gross N, da Silveira Pontes L, Picon-Cochard C, Soussana JF (2009) Trade-off between root nitrogen acquisition and shoot nitrogen utilization across 13 cooccurring pasture grass species. Funct Ecol 23:668-679

Morris DL (1948) Quantitative determination of carbohydrates with Dreywood's anthrone reagent. Science 107:254-255

> Müller I, Schmid B, Weiner J (2000) The effect of nutrient availability on biomass allocation patterns in 27 species of herbaceous plants. Perspect Plant Ecol Evol Syst 3: 115-127

Nicholson SA, Levey RA, Clute PR (1975) Macrophytesediment relationships in Chautaugua Lake. Verh Int Ver Theor Angew Limnol 19:2758-2764

Puijalon S, Piola F, Bornette G (2008) Abiotic stresses increase plant regeneration ability. Evol Ecol 22:493-506

Rogers KH, Breen CM (1980) Growth and reproduction of Potamogeton crispus in a South African lake. J Ecol 68: 561-571

Santamaría L (2002) Why are most aquatic plants widely distributed? Dispersal, clonal growth and small-scale heterogeneity in a stressful environment. Acta Oecol 23: $137-154$

Santamaría L, Rodríguez-Gironés MA (2002) Hiding from swans: optimal burial depth of sago pondweed tubers foraged by Bewick's swans. J Ecol 90:303-315

Sastroutomo SS (1981) Turions formation, dormancy and germination of curly pondweed, Potamogeton crispus L. Aquat Bot 10:161-173

Schmid B, Polasek W, Weiner J, Krause A, Stoll P (1994) Modeling of discontinuous relationship in biology with censored regression. Am Nat 143:494-507

> Slade AJ, Hutchings MJ (1987) The effect of nutrient availability on foraging in the clonal herb Glechoma hederacea. J Ecol 75:95-112

> Smith CC, Fretwell SD (1974) The optimal balance between size and number of offspring. Am Nat 108:499-506

Smith DH, Madsen JD, Dickson KL, Beitinger TL (2002) Nutrient effects on autofragmentation of Myriophyllum spicatum. Aquat Bot 74:1-17

Spencer DF, Ksander GG (1996) Growth and carbon utilization by sprouted propagules of two species of submersed rooted aquatic plants grown in darkness. Hydrobiologia 317:69-78

Stoll P, Egli P, Schmid B (1998) Plant foraging and rhizome growth patterns of Solidago altissima in response to mowing and fertilizer application. J Ecol 86:341-354

Sugiyama S, Bazzaz FA (1998) Size dependence of reproductive allocation: the influence of resource availability, competition and genetic identity. Funct Ecol 12:280-288

> Suzuki JI, Stuefer JF (1999) On the ecological and evolutionary significance of storage in clonal plants. Plant Species Biol 14:11-17

> Takada T, Nakajima H (1996) The optimal allocation for seed reproduction and vegetative reproduction in perennial plants: an application to the density-dependent transition matrix model. J Theor Biol 182:179-191

Vojtíšková L, Munzarová E, Votrubová O, Řihová A, Juřicová B (2004) Growth and biomass allocation of sweet flag (Acorus calamus L.) under different nutrient conditions. Hydrobiologia 518:9-22 
Wang J, Yu D (2007) Influence of sediment fertility on morphological variability of Vallisneria spiralis L. Aquat Bot 87:127-133

Weber JA, Noodén LD (2005) The causes of sinking and floating in turions of Myriophyllum verticillatum. Aquat Bot 83:219-226

Werger MJA, Huber H (2006) Tuber size variation and organ preformation constrain growth responses of a spring geophyte. Oecologia 147:396-405

Woolf TE, Madsen JD (2003) Seasonal biomass and carbohydrate allocation patterns in Southern Minnesota curlyleaf pondweed populations. J Aquat Plant Manag 41:113-118

Worley AC, Harder LD (1996) Size-dependent resource allocation and costs of reproduction in Pinguicula vulgaris (Lentibulariaceae). J Ecol 84:195-206

Wu J, Cheng S, Liang W, He F, Wu Z (2009) Effects of sediment anoxia and light on turion germination and early growth of Potamogeton crispus. Hydrobiologia 628:

Editorial responsibility: Hans Heinrich Janssen, Oldendorf/Luhe, Germany
$111-119$

Xiao K, Yu D, Wang J (2006) Habitat selection in spatially heterogeneous environments: a test of foraging behaviour in the clonal submerged macrophyte Vallisneria spiralis. Freshw Biol 51:1552-1559

Xie D, Yu D (2011) Size-related auto-fragment production and carbohydrate storage in auto-fragment of Myriophyllum spicatum L. in response to sediment nutrient and plant density. Hydrobiologia 658:221-231

Xie D, Yu D, Yu LF, Liu CH (2010) Asexual propagations of introduced exotic macrophytes Elodea nuttallii, Myriophyllum aquaticum, and $M$. propinquum are improved by nutrient-rich sediments in China. Hydrobiologia 655: 37-47

Xie Y, Yu D, Geng X (2003) Effects of elevated $\mathrm{CO}_{2}$ concentration on phenotypic, physiological and biochemical characteristics of submersed plant Potamogeton crispus Leaf. Acta Phytoecol Sin 27:218-222

Submitted: November 15, 2010; Accepted: August 8, 2011 Proofs received from author(s): October 19, 2011 